\title{
Green Extraction Optimization of Bioactive Compounds from Rosemary (Rosmarinus officinalis L.) Using Response Surface Methodology
}

\author{
Tiago A. M. Lopes, ${ }^{a}$ Antonio C. Godoy, ${ }^{a}$ Nayane B. M. Sinosaki, ${ }^{a}$ Patrícia D. S. Santos, ${ }^{a}$ \\ Lucas U. R. Chiavelli, ${ }^{a}$ Roberta Silveira, ${ }^{\circledR b}$ Bruno H. Figueiredo, ${ }^{a}$ Jesuí V. Visentainer ${ }^{\circledR a}$ \\ and Oscar $O$. Santos ${ }^{\circledR} * a$ \\ aPrograma de Pós-Graduação em Química, Universidade Estadual de Maringá, \\ 87020-900 Maringá-PR, Brazil

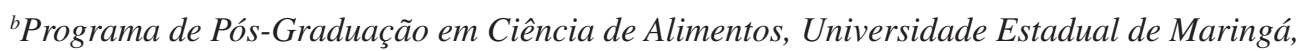 \\ 87020-900 Maringá-PR, Brazil
}

\begin{abstract}
Rosemary (Rosmarinus officinalis L.) is known for its bioactive compounds with high antioxidant potential and pharmacological properties, such as antibacterial, antidepressant and anti-inflammatory. These properties are attributed to the presence of (poly)phenolic compounds. In the literature there is no extraction of these compounds with a totally non-toxic solvent, capable of applying the extract directly to the food. This work aimed to optimize the extraction conditions of bioactive compounds from the rosemary leaves using water as solvent. According to the analysis of variance parameters, a cubic model of high order of significance was obtained with adjusted $\mathrm{R}^{2}$ (R squared) $>0.947$. The optimal conditions of the antioxidant potential for conventional and ultrasonic agitation were: temperature $70{ }^{\circ} \mathrm{C}, 30 \mathrm{~min}$ of extraction and the solvent/solute ratio of 25, resulting in an antioxidant potential of 6861 and $7126 \mu \mathrm{mol} \mathrm{\textrm {L } ^ { - 1 }}$ Trolox, respectively. The electrospray ionization mass spectrometry (ESI(-)-MS/MS) analysis showed the presence of antioxidant compounds such as: carnosol $(\mathrm{m} / \mathrm{z}, 329.20)$, rosmanol $(\mathrm{m} / \mathrm{z}, 345.03)$ and rosmarinic $(\mathrm{m} / \mathrm{z}, 359.14)$ acids. The response surface methodology evaluated the influence of the main parameters of the bioactive compounds extraction from rosemary using only water as solvent, in addition to the use of less time and sample mass, resulting in lower cost.
\end{abstract}

Keywords: bioactive compounds, central composite planning, less environmental impact

\section{Introduction}

Aromatic herbs have several bioactive compounds capable of eliminating free radicals to interrupt the lipid oxidative chain reaction in food products. ${ }^{1}$ Rosemary is a plant from the Mediterranean region with numerous health benefits, such as flu, asthma, blood pressure and rheumatic pains prevention, which are attributed to the presence of phenolic compounds, especially rosmarinic acid, carnosic acid, carnosol and rosmanol. ${ }^{2,3}$

Several studies ${ }^{4-9}$ are found in the literature on the conditions for the bioactive compounds extraction from rosemary, and among the main studies, the best extraction technique, the mass, the temperature, the solvents were investigated.

Among the extraction techniques commonly employed,

*e-mail: oliveirasantos.oscardeoliveira@gmail.com we can mention: assisted ultrasound extraction (sonication), conventional agitation, mechanical agitation and Soxhlet extraction with times ranging from $10 \mathrm{~min}$ to $8 \mathrm{~h}$ and using sample quantities from 0.15 to $40 \mathrm{~g} \cdot{ }^{4-11}$

The studies ${ }^{4-9}$ found in the literature employ extraction methodologies that use toxic solvents, such as methanol and chloroform, which are environmentally unfavorable, and also prevent the direct application of these extracts in food, in addition to the long time of the extraction process.

Extraction is an essential step to obtain bioactive compounds. ${ }^{10}$ Due to the differences in the physicochemical properties of these compounds, it is important to evaluate the effect of factors that influence the extraction process, such as temperature, extraction time and solvent/solute ratio. ${ }^{12-15}$

In order to obtain the bioactive with high yield, it is necessary to optimize the extraction of phenolic compounds from the response surface methodology, being applied 
statistical mechanisms to evaluate all the variables involved in the extraction process to define the ideal conditions of this process, which proposes the reduction of experimental time, as well as its ability to assess the effect of different sources of influence and its interactions on the response. ${ }^{8-16}$

In the context of green chemistry, it is necessary to consume less toxic solvents and lessen the environmental impact. Thus, the present work employed water as solvent due to its low cost, high availability, non-toxicity, polarity similar to the main bioactive compounds present in $R$. officinalis L., which allows the direct use of the extract obtained in food.

\section{Experimental}

\section{Sampling and sample preparation}

Samples of R. officinalis L. were collected in Florida, PR, Brazil (2305'12.0” S, 51 $57^{\prime}$ '01.2” W). The samples were dried in the shade at room temperature $\left(25^{\circ} \mathrm{C}\right)$ to reduce humidity and the leaves were separated from the stem. The leaves were ground using a Manesco and Ranieri knife mill (Piracicaba, Brazil) and finally the particles were passed through an $80 \mathrm{~mm}$ sieve and weighed using the Shimadzu analytical scale model ATY 224 (Tokyo, Japan).

The sample was vacuum packed in a metallic package and refrigerated at $-18{ }^{\circ} \mathrm{C}$ for further analysis.

\section{Experimental design and extraction}

A central composite design (CCD) was developed to assess the influence of the variables: time, temperature, stirring mode and solvent/solute ratio. The CCD, associated with the surface response methodology (SRM), was developed by the Design Expert software, ${ }^{17}$ to study regression analysis of experimental data and draw the response surface graph. The time levels -1 to +1 were 30 to $100 \mathrm{~min}$, respectively. Temperature levels -1 to +1 were 40 to $70{ }^{\circ} \mathrm{C}$ and the solvent/solute ratio levels -1 to +1 were 25 to 75 , respectively. The agitation mode was evaluated as a qualitative variable. The axial points $( \pm \alpha)$ for the rotational system (constant $\mathrm{k}<5$ ) were \pm 1.4142 , used to calculate the quadratic terms. Five repetitions were performed at the central point, totaling 40 experiments.

Analysis of variance (ANOVA) was used to estimate the statistical parameters, once the desired range value of the variables (factors) is defined, it is coded as \pm 1 for the factor points, 0 for central points and $\pm \alpha$ for the axial points, according to Table 1.

The extraction process was conducted according to the conditions established in the experimental design; $25 \mathrm{~mL}$ of distilled water as solvent in two forms of
Table 1. Variables and levels used in the experimental design

\begin{tabular}{lccccc}
\hline \multirow{2}{*}{ Variable } & \multicolumn{5}{c}{ Level } \\
\cline { 2 - 6 } & $-\alpha$ & -1 & 0 & +1 & $+\alpha$ \\
\hline Temperature $/{ }^{\circ} \mathrm{C}$ & 30 & 40 & 55 & 70 & 80 \\
time / min & 6 & 30 & 65 & 100 & 124 \\
Solvent/solute ratio & 8 & 25 & 50 & 75 & 92 \\
\hline
\end{tabular}

$\pm \alpha$ : axial points; \pm : factorial points; 0 : central points.

stirring: ultrasonic and conventional stirring. Ultrasonic shaking was performed using the El P Phantom Elma Schmidbauer model (Singen, Germany) with power of $80 \mathrm{~W}$ and frequency of $37 \mathrm{kHz}$. For conventional stirring it was used the FIS752-2 magnetic stirrer, Fisaton (São Paulo, Brazil). Both extractions were performed in the light absence and controlled temperature, which was evaluated with calibrated digital thermometer model TE-400, Instrutherm (São Paulo, Brazil). Subsequently, the extracts were conducted for the determination of the scPHenger DPPH (1,1-diphenyl-2-picrylhydrazyl) activity test ("Determination of antioxidant activity by the DPPH ${ }^{\bullet}$ method" sub-section) and the identification of antioxidant compounds by electrospray ionization mass spectrometry (ESI-MS/MS) ("Identification of antioxidant compounds by mass spectrometry (ESI-MS)" sub-section). Additionally, the extracts obtained under ideal conditions were lyophilized in the Lyophilizer Alpha 1-2 LDplus model, Martin Christ (Osterode am Harz, Germany) and stored at $-18{ }^{\circ} \mathrm{C}$ until analysis.

Determination of antioxidant activity by the $\mathrm{DPPH} \cdot \operatorname{method}$

This simpler and cheaper technique was used to evaluate in which design there was a greater response of the antioxidant potential.

Therefore, it was determined by UV-Vis spectrophotometry with reading of $517 \mathrm{~nm}$ in a Genesis $10 \mathrm{UV}$ UV-Vis spectrophotometer, Thermo Scientific (Waltham, USA). ${ }^{18,19}$ Assisted by the analytical curve (equation 1) following the linearity criteria and linear pre-calculated working range, ${ }^{20}$ with seven concentration levels of the ( \pm ) 6-hydroxy 2,5,7,8-tetramethylcroman-2 carboxylic acid solution (Trolox) (Sigma-Aldrich, São Paulo, Brazil), ranging from 50 to $2000 \mu \mathrm{mol} \mathrm{L} \mathrm{L}^{-1}$. The results were

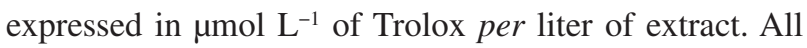
data were performed in triplicate. The assay abosorbance was named ABS.

$\left[\mu \mathrm{mol} \mathrm{L}{ }^{-1}\right.$ Trolox $]=\frac{(\mathrm{ABS}-0.6554)}{-0.0003}, \mathrm{R}^{2}=0.992$ 
Identification of antioxidant compounds by mass spectrometry (ESI-MS)

The identification of the main compounds present in the extract of $R$. officinalis L. was carried out in the assay that presented the greatest antioxidant potential through the electrospray mass spectrometer by direct infusion (ESI-MS XevoAcquity§R (Waters, Milford, MA, USA)) operating in negative mode. The spectra were acquired in scan mode using $\mathrm{m} / \mathrm{z}$ ranging from 300 to 400 . For the extract infusion, $50 \mathrm{mg}$ of the extract was dissolved in $10 \mathrm{~mL}$ of Milli-Q water (Millipore, Bedford, USA), then $1 \mathrm{~mL}$ of this solution was transferred to a flask and added with $10 \mu \mathrm{L}$ of ammonium hydroxide solution (7.50 $\mathrm{mmol} \mathrm{L}^{-1}$ ). The chromatographic separation was carried out on a C18 column $(1.8 \mu \mathrm{m}, 2.1 \times 100 \mathrm{~mm}$, Agilent Acquity UPLC ${ }^{\circledR}$ HSS T3, Santa Clara, USA) with a gradient system consisting of mobile phase solution $\mathrm{A}$ ( $0.1 \%$ formic acid in water) and solution $\mathrm{B}$ (acetonitrile)

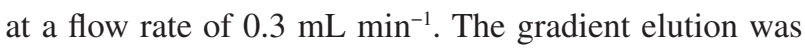
programmed as follows: 0.0-6.0 min, 60\% A-15\% A; 6.0-8.0 min, 15\% A-5\% A; 8.0-9.0 min, 5\% A-60\% A. The column temperature was set at $30{ }^{\circ} \mathrm{C}$. Each injection operated for 9 min and the injection volume was $10 \mu \mathrm{L}$. The working conditions of the ionization source were as follows: capillary voltage, $3 \mathrm{kV}$; source temperature, $150{ }^{\circ} \mathrm{C}$; cone gas flow, $30 \mathrm{~L} \mathrm{~h}^{-1}$; flow rate of desolvation gas, $500 \mathrm{~L} \mathrm{~h}^{-1}$; and desolvation temperature, $400{ }^{\circ} \mathrm{C}$.

The ESI source, negative ionization mode and multiple reaction monitoring (MRM) technique were employed. The MS/MS experiments were performed with collision energy between 11-55 and fragments between 120-184. Data acquisition was performed with MassLynx v. 4.1 software.

\section{Results and Discussion}

\section{Experimental design}

The results of the antioxidant potential obtained for each experiment in the experimental design are displayed in Table 2.

The optimization of the extraction conditions for the bioactive compounds in rosemary was performed by evaluating the effect of four independent variables: temperature, time, solvent/solute ratio and agitation form. For this, an experimental planning by central composite design was generated in order to obtain the best conditions.

According to the different experimental tests performed, the highest result obtained for conventional agitation was produced in test 22 , with antioxidant potential of
$6861 \mu \mathrm{mol} \mathrm{L}{ }^{-1}$ Trolox, while for ultrasonic agitation the highest result was in test 13 , with antioxidant potential of $7786 \mu \mathrm{mol} \mathrm{L}{ }^{-1}$ Trolox.

The extraction by ultrasound resulted in the highest antioxidant potential due to greater agitation, which offers good analyte recovery, through simple equipment and easy operation. Due to its advantages, ultrasound is widely used to increase the reaction yield, since the cavitation generated from the ultrasound (formation, increase and implosion of bubbles in the reaction medium) provides more energy to the system causing greater miscibility of the reagents and consequently increasing the contact surface between the molecules making the reaction more effective. ${ }^{21}$

The experimental data were analyzed in different models (two factor interaction (2FI), linear, quadratic and cubic) to verify which one would present the best result. From the results described in Table 2, the model that best represents the antioxidant potential of rosemary is the cubic model.

To verify the experimental results and the interaction between the factors, ANOVA and the response surface were used and from Table 3 the results showed that the $F$-value for the model is of 51.66 being significant.

The equation obtained for the cubic model is presented in equation 2 , with correlation coefficient $\left(\mathrm{R}^{2}\right)$ of 0.966 .

$\mathrm{Y}=1542.7+665.23(\mathrm{~A})+218.330(\mathrm{CD})-$

$261.83\left(\mathrm{~B}^{2}\right)+923.75\left(\mathrm{C}^{2}\right)+467.27\left(\mathrm{AB}^{2}\right)$

where $\mathrm{Y}$ is the antioxidant potential; $\mathrm{A}$ is the temperature; $\mathrm{B}$ is the time and $\mathrm{C}$ is the solvent/solute ratio.

The terms $\mathrm{A}, \mathrm{CD}, \mathrm{B}^{2}, \mathrm{C}^{2}$ and $\mathrm{AB}^{2}$ presented probability less than 0.0500 indicating that it is significant for the model. However, values greater than 0.100 indicate nonsignificant model terms.

Adequate precision measures the signal for the noise rate, and a ratio greater than 4 is desirable, for this particular experimental planning the ratio presented was 25.89 , indicating that the signal was adequate and the model was significant for the antioxidant potential.

Figure 1 illustrates the expected values in relation to the values obtained for the experimental design.

According to Figure 1, predicted values are very close to the values obtained, that is, points are close to the line indicating well-adjusted model.

Figure 2 shows the surface response obtained in experimental design, evidencing that the antioxidant potential increase of the extract occurs with the increase in temperature and when the solvent/solute ratio decrease. As the temperature increases, the solubility of the compounds 
Table 2. Factors, levels and results of DPPH ${ }^{\bullet}$ radical scavenging activity for the experimental design procedure

\begin{tabular}{|c|c|c|c|c|c|}
\hline Assay & Temperature $/{ }^{\circ} \mathrm{C}$ & time / min & Solvent/solute ratio & Agitation form & $\begin{array}{c}\text { DPPH• radical } \\
\text { scavenging activity / } \\
\left(\mu \mathrm{mol} \mathrm{L}{ }^{-1} \text { Trolox }\right)\end{array}$ \\
\hline 1 & $40(-1)$ & $30(-1)$ & $25(-1)$ & ultrasound & 1767 \\
\hline 2 & $70(+1)$ & $30(-1)$ & $25(-1)$ & ultrasound & 7126 \\
\hline 3 & $40(-1)$ & $100(+1)$ & $25(-1)$ & ultrasound & 1914 \\
\hline 4 & $70(+1)$ & $100(+1)$ & $25(-1)$ & ultrasound & 6420 \\
\hline 5 & $40(-1)$ & $30(-1)$ & $75(+1)$ & ultrasound & 765 \\
\hline 6 & $70(+1)$ & $30(-1)$ & $75(+1)$ & ultrasound & 2870 \\
\hline 7 & $40(-1)$ & $100(+1)$ & $75(+1)$ & ultrasound & 1217 \\
\hline 8 & $70(+1)$ & $100(+1)$ & $75(+1)$ & ultrasound & 2795 \\
\hline 9 & $30(-\alpha)$ & $65(0)$ & $50(0)$ & ultrasound & 462 \\
\hline 10 & $80(+\alpha)$ & $65(0)$ & $50(0)$ & ultrasound & 4273 \\
\hline 11 & $55(0)$ & $6(-\alpha)$ & $50(0)$ & ultrasound & 1676 \\
\hline 12 & $55(0)$ & $124(+\alpha)$ & $50(0)$ & ultrasound & 2375 \\
\hline 13 & $55(0)$ & $65(0)$ & $8(-\alpha)$ & ultrasound & 7786 \\
\hline 14 & $55(0)$ & $65(0)$ & $92(+\alpha)$ & ultrasound & 1100 \\
\hline 15 & $55(0)$ & $65(0)$ & $50(0)$ & ultrasound & 1748 \\
\hline 16 & $55(0)$ & $65(0)$ & $50(0)$ & ultrasound & 3167 \\
\hline 17 & $55(0)$ & $65(0)$ & $50(0)$ & ultrasound & 1414 \\
\hline 18 & $55(0)$ & $65(0)$ & $50(0)$ & ultrasound & 2395 \\
\hline 19 & $55(0)$ & $65(0)$ & $50(0)$ & ultrasound & 1392 \\
\hline 20 & $55(0)$ & $65(0)$ & $50(0)$ & ultrasound & 2088 \\
\hline 21 & $40(-1)$ & $30(-1)$ & $25(-1)$ & conventional & 1587 \\
\hline 22 & $70(+1)$ & $30(-1)$ & $25(-1)$ & conventional & 6861 \\
\hline 23 & $40(-1)$ & $100(+1)$ & $25(-1)$ & conventional & 722 \\
\hline 24 & $70(+1)$ & $100(+1)$ & $25(-1)$ & conventional & 6342 \\
\hline 25 & $40(-1)$ & $30(-1)$ & $75(+1)$ & conventional & 540 \\
\hline 26 & $70(+1)$ & $30(-1)$ & $75(+1)$ & conventional & 2312 \\
\hline 27 & $40(-1)$ & $100(+1)$ & $75(+1)$ & conventional & 543 \\
\hline 28 & $70(+1)$ & $100(+1)$ & $75(+1)$ & conventional & 2941 \\
\hline 29 & $30(-\alpha)$ & $65(0)$ & $50(0)$ & conventional & 440 \\
\hline 30 & $80(+\alpha)$ & $65(0)$ & $50(0)$ & conventional & 3878 \\
\hline 31 & $55(0)$ & $6(-\alpha)$ & $50(0)$ & conventional & 1333 \\
\hline 32 & $55(0)$ & $124(+\alpha)$ & $50(0)$ & conventional & 1860 \\
\hline 33 & $55(0)$ & $65(0)$ & $8(-\alpha)$ & conventional & 6227 \\
\hline 34 & $55(0)$ & $65(0)$ & $92(+\alpha)$ & conventional & 2847 \\
\hline 35 & $55(0)$ & $65(0)$ & $50(0)$ & conventional & 1744 \\
\hline 36 & $55(0)$ & $65(0)$ & $50(0)$ & conventional & 1527 \\
\hline 37 & $55(0)$ & $65(0)$ & $50(0)$ & conventional & 1887 \\
\hline 38 & $55(0)$ & $65(0)$ & $50(0)$ & conventional & 2034 \\
\hline 39 & $55(0)$ & $65(0)$ & $50(0)$ & conventional & 1748 \\
\hline 40 & $55(0)$ & $65(0)$ & $50(0)$ & conventional & 1540 \\
\hline
\end{tabular}

DPPH: 1,1-diphenyl-2-picrylhydrazyl; \pm 1 : factorial points; $\pm \alpha$ : axial points; 0 : central points. 
Table 3. Parameters of the ANOVA model for the proposed experimental design

\begin{tabular}{|c|c|c|c|c|c|c|}
\hline & Quadratic sum & DF & Quadratic mean & $F$-value & Prob $>F$ & \\
\hline Model & $1.48 \times 10^{8}$ & 14 & $1.07 \times 10^{7}$ & 51.66 & $<0.0001$ & S \\
\hline A & $9.11 \times 10^{6}$ & 1 & $9.11 \times 10^{6}$ & 44.04 & $<0.0001$ & S \\
\hline B & 66100.00 & 1 & 66100.00 & 0.32 & 0.5771 & NS \\
\hline $\mathrm{C}$ & $1.61 \times 10^{5}$ & 1 & $1.61 \times 10^{5}$ & 0.78 & 0.3862 & NS \\
\hline $\mathrm{D}$ & $8.50 \times 10^{5}$ & 1 & $8.50 \times 10^{5}$ & 4.11 & 0.0534 & NS \\
\hline $\mathrm{AB}$ & 10404.00 & 1 & 10404.00 & 0.050 & 0.8244 & NS \\
\hline $\mathrm{AC}$ & $1.3 \times 10^{6}$ & 1 & $1.3 \times 10^{6}$ & 6.28 & 0.8204 & NS \\
\hline $\mathrm{BC}$ & $5.446 \times 10^{5}$ & 1 & $5.446 \times 10^{5}$ & 2.63 & 0.1173 & NS \\
\hline $\mathrm{CD}$ & $1.301 \times 10^{6}$ & 1 & $1.301 \times 10^{6}$ & 6.28 & 0.0191 & S \\
\hline $\mathrm{A}^{2}$ & $4.166 \times 10^{5}$ & 1 & $4.166 \times 10^{5}$ & 2.01 & 0.1683 & NS \\
\hline $\mathrm{B}^{2}$ & $1.173 \times 10^{6}$ & 1 & $1.173 \times 10^{6}$ & 5.66 & 0.0253 & S \\
\hline $\mathrm{C}^{2}$ & $6.44 \times 10^{6}$ & 1 & $6.44 \times 10^{6}$ & 31.07 & $<0.0001$ & S \\
\hline $\mathrm{A}^{2} \mathrm{C}$ & 1791.66 & 1 & 1791.66 & 0.008 & 0.9266 & NS \\
\hline $\mathrm{AB}^{2}$ & $3.22 \times 10^{6}$ & 1 & $3.22 \times 10^{6}$ & 15.56 & $<0.0001$ & S \\
\hline $\mathrm{B}^{2} \mathrm{C}$ & 603.06 & 1 & 603.06 & 0.002 & 0.9574 & NS \\
\hline Residue & $5.17 \times 10^{6}$ & 25 & $2.07 \times 10^{5}$ & - & - & - \\
\hline Lack of fit & $3.15 \times 10^{6}$ & 17 & $1.85 \times 10^{5}$ & 0.73 & 0.7192 & NS \\
\hline Pure error & $2.02 \times 10^{6}$ & 8 & $2.53 \times 10^{5}$ & - & - & - \\
\hline
\end{tabular}

DF: degree of freedom; Prob $>F$ : probability value that is associated with the value of $F$; A: temperature; B: time; C: solvent/solute ratio; D: agitation with sonication; $\mathrm{AB}$ : interaction between temperature and time; $\mathrm{AC}$ : interaction between temperature and solvent/solute ratio; $\mathrm{BC}$ : interaction between time and solvent/solute ratio; CD: interaction between solvent/solute ratio and agitation with sonication; S: significant; NS: not significant.

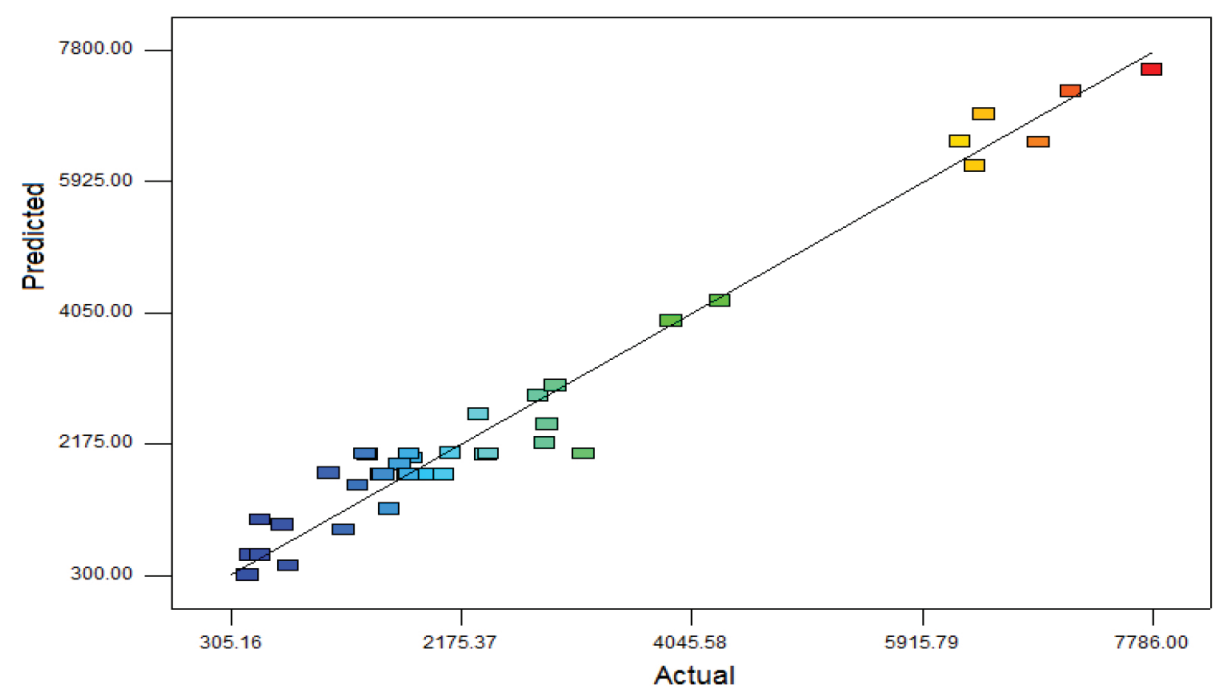

Figure 1. Predicted model values $v s$. experimental values for proposed delineated experiment.

increases, resulting in better solvent permeation on the substrate and, consequently, greater extraction efficiency.

The decrease in the solvent/solute ratio is due to the fact that, in high ratios, the solvent is saturated with the compounds, preventing it from being extracted.

In order to optimize the experimental conditions for the bioactive compounds extraction from rosemary, the Design Expert program ${ }^{17}$ generated several experiments to verify the method desirability. Table 4 shows the results of the $\mathrm{DPPH}^{\bullet}$ radical scavenging activity obtained under the ideal conditions proposed by the experimental design applied in three experiments.

It is observed that all values obtained are within the proposed range, shown in the table, taking into account the suggested value for the antioxidant potential and the coefficient of variation obtained in this design. Thus, the 


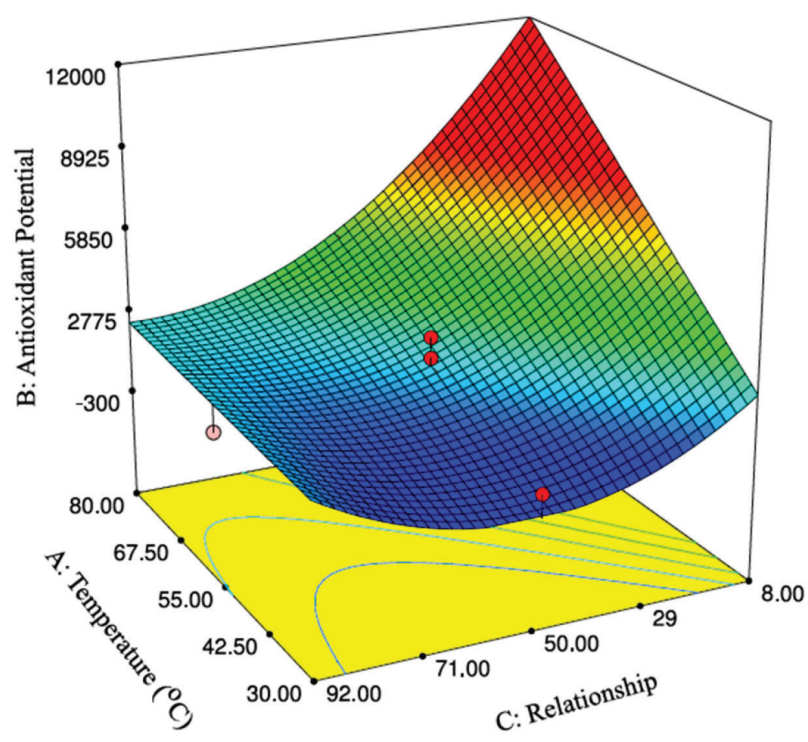

Figure 2. 3D graph of response surface for the experimental design proposed.

model fits satisfactorily with the extraction data of the rosemary antioxidant compounds.

\section{Antioxidants identified by ESI-MS}

The direct infusion by ESI(-)-MS/MS was carried out in order to identify the main antioxidant compounds present in $R$. officinalis L. The polyphenol molecules contain at least one hydroxyl group. Therefore, the MS data was acquired in negative ionization mode. Consequently, antioxidant compounds were identified based on the analysis of deprotonated ions $[\mathrm{M}-\mathrm{H}]^{-}$.

Figure 3 shows the fingerprint of the antioxidant compounds present in the aqueous extract of rosemary obtained under the ideal conditions of extraction. Three polyphenols of interest distributed in the analyzed extracts were identified.

Figure 4 shows the main antioxidant compounds identified by ESI(-)-MS/MS using as precursor product ion transition: (a) $m / z 301.09$ for rosmanol acid; (b) $m / z 285.27$ for carnosol and (c) $\mathrm{m} / \mathrm{z}, 359$ for rosmarinic acid. The results are in line with those observed in the literature. ${ }^{21-25}$

\section{Conclusions}

Central composite planning combined with response

Table 4. $\mathrm{DPPH} \bullet$ radical scavenging activity results obtained under ideal conditions

\begin{tabular}{lccccccc}
\hline \multirow{2}{*}{ Assay } & Temperature $/{ }^{\circ} \mathrm{C}$ & time $/$ min & Solvent/solute ratio & Heating & \multicolumn{2}{c}{$\mathrm{DPPH}^{\bullet}$ radical scavenging activity $/\left(\mu \mathrm{mol} \mathrm{L} \mathrm{C}^{-1}\right.$ Trolox $)$} \\
\hline 1 & 80 & 63 & 9.3 & conventional & $10705(8456-12953)$ & $9728 \pm 1.10$ \\
2 & 80 & 51 & 14.67 & ultrasound & $10494(8291-12698)$ & $9334 \pm 0.88$ \\
3 & 80 & 111 & 22.66 & conventional & $8076(6380-9772)$ & $7073 \pm 1.71$ \\
\hline
\end{tabular}

DPPH: 1,1-diphenyl-2-picrylhydrazyl.

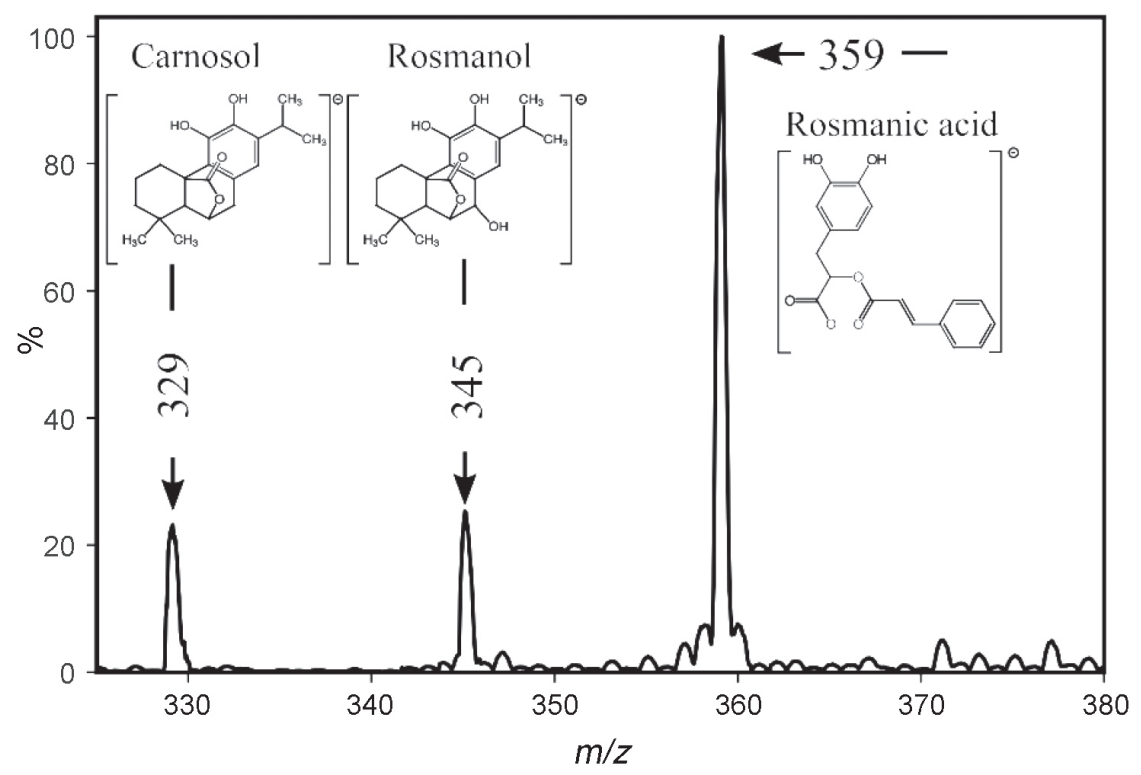

Figure 3. Spectra obtained by ESI(-)-MS/MS of the main bioactive compounds present and isolated in R. officinalis L. 

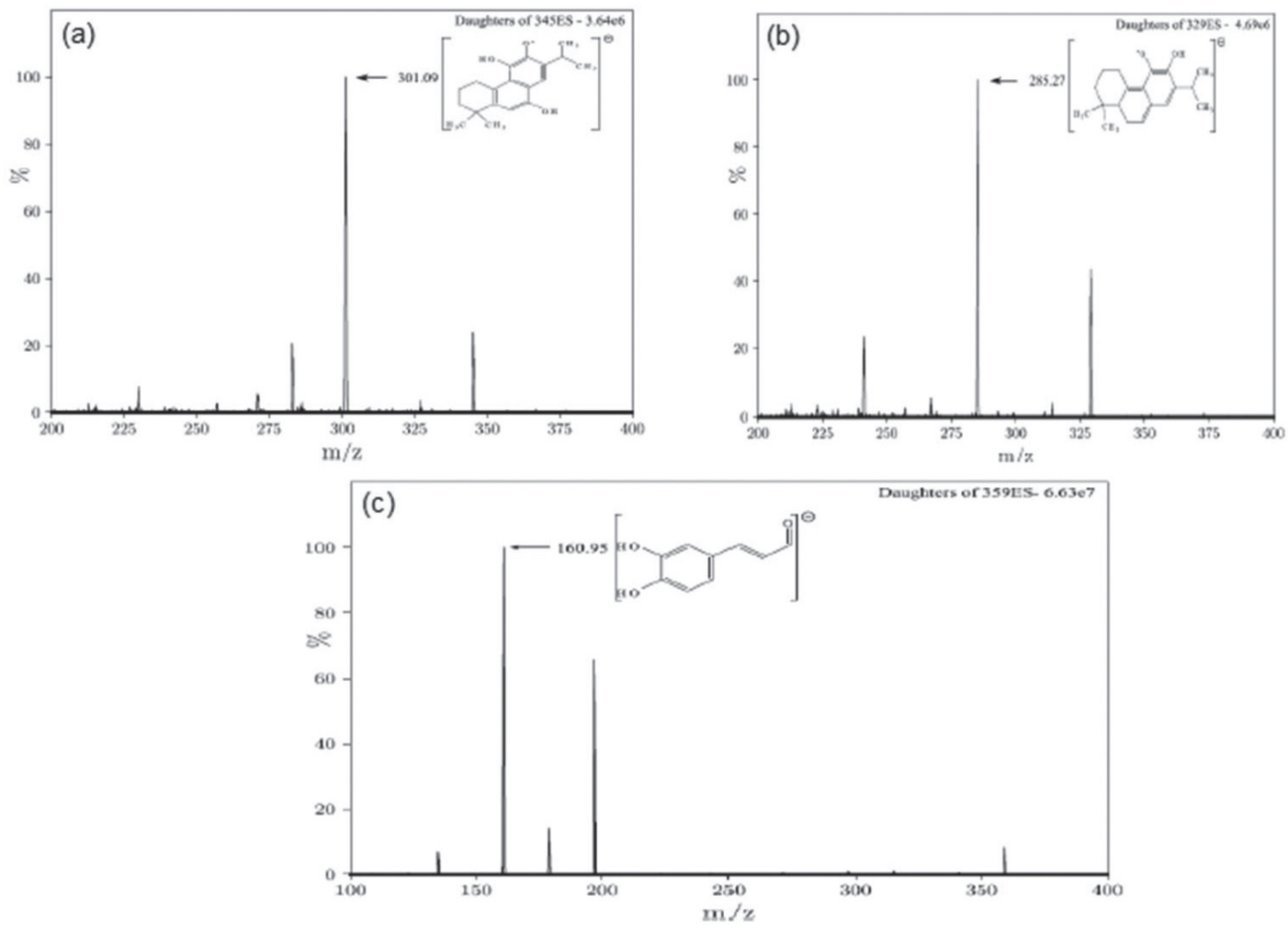

Figure 4. ESI(-)-MS/MS mass spectrum fragmentation for the main antioxidants compounds present and isolated in the R. officinalis L., being (a) rosmanol; (b) carnosol and (c) rosmarinic acid.

surface methodology was applied efficiently in order to optimize the variables of a new technique for extracting bioactive compounds in the aqueous extract of rosemary leaves, promoting the reduction of process steps, time and operational cost and improving process performance. Furthermore, the extraction using water was considered the most suitable for this process and through the technique by direct infusion via ESI(-)-MS/MS it was possible to identify the antioxidant compounds carnosol, rosmanol and rosmarinic acids present in the aqueous extracts. In this way, it can be considered as a simplified, inexpensive and efficient green extraction process without the use of toxic solvents, allowing the direct use of the extract obtained in food.

\section{Supplementary Information}

Supplementary data are available free of charge at http://jbcs.sbq.org.br as PDF file.

\section{Acknowledgments}

We would like to thank CAPES (Coordenação de Aperfeiçoamento de Pessoal de Nível Superior) for the financial support.

\section{Author Contributions}

Tiago A. M. Lopes was responsible for the visualization, writing original draft, review and editing; Antonio C. Godoy for the data curation and visualization; Patrícia Santos for the formal analysis and investigation; Nayane B. M. Sinosaki for the formal analysis and writing original draft; Lucas U. R. Chiavelli for the formal analysis and writing original draft; Roberta Silveira for the formal analysis and writing original draft; Bruno $\mathrm{H}$. Figueiredo for the formal analysis and investigation; Jesuí V. Visentainer for the conceptualization and supervision; Oscar O. Santos for the funding acquisition and supervision.

\section{References}

1. http://www.fao.org/3/t0251e/T0251E09.htm, accessed in June 2020.

2. Cordeiro, A. M. T. M.; Medeiros, M. L.; Souza, G. A.; J. Therm. Anal. Calorim. 2013, 114, 827.

3. Jacotet-Navarro, M.; Rombaut, N.; Fabiano-Tixier, A. S.; Ultrason. Sonochem. 2015, 27, 102.

4. Albu, S.; Joyce, E.; Paniwnuk, L.; Lorimer, J. P.; Mason, T. J.; Ultrason. Sonochem. 2004, 11, 261. 
5. Hernández-Hernández, E.; Ponce-Alquicira, E.; JaramilloFlores, M. E.; Guerrero Legarreta, I.; Meat Sci. 2009, 81, 410.

6. Hendel, N.; Larous, L.; Belbey, L.; Int. Food Res. J. 2016, 23, 1725.

7. Hossain, M. B.; Barry-Ryan, C.; Martin-Diana, A. B.; Bruton, N. P.; Food Chem. 2011, 126, 339.

8. Ôzcan, M.; Grasas Aceites 1999, 50, 355.

9. Santos, R. D.; Shtty, K.; Cechini, A. L.; Miglioranza, L. H. S.; Cienc. Agrar. 2012, 2, 655.

10. Yesil-Celiktas, O.; Nartop, P.; Gurel, A.; Bedir, E.; VardarSukan, F.; J. Plant Physiol. 2007, 164, 1536.

11. Topuz, O. K.; Gokoglu, N.; Yerlikaya, P.; Ucak, I.; Gumus, B.; J. Aquat. Food Prod. Technol. 2016, 25, 414.

12. Liu, R.; Zheng, W.; Li, J.; Wang, L. C.; Food Chem. 2015, 167 , 484.

13. Nicácio, A. E.; Maldaner, L.; Visentainer, J. V.; Food Anal. Methods 2017, 10, 2718.

14. Thoo, Y.; Ho, S. H.; Liang, Y. J.; Food Chem. 2010, 120, 290.

15. Tomaz, I.; Bándic, M. L.; Preiner, D.; Stupic, D.; Phytochem. Anal. 2016, 27, 13.

16. Ye, C.; Jiang, C.; Carbohydr. Polym. 2011, 84, 495.
17. Design-Expert, version 7.1; Stat-Ease Inc., Minneapolis, MN, USA, 2007.

18. Brand-Williams, W.; Cuvelier, M. E.; Berset, C. L. W. T.; LWT--Food Sci. Technol. 1995, 28, 25.

19. Ma, X.; Wu, H.; Yao, Q.; Sci. Hortic. 2011, 129, 102.

20. International Conference on Harmonization (ICH); Validation of Analytical Procedures: Text and Methodology Q2 (R1); ICH: London, 2005.

21. Maran, J. P.; Priya, B.; Ultrason. Sonochem. 2015, 23, 192.

22. Chkhikvishvili, I.; Sanikidze, T.; Gogia, N.; Mchedlishvili, T.; Enukidze, M.; Machavariani, M.; Vinokur, Y.; Rodov, V.; Oxid. Med. Cell. Longevity 2013, 456253.

23. Mena, P.; Cirlini, M.; Tassotti, M.; Herrlinger, A. K.; Dall'Asta, C.; Del Rio, D.; Molecules 2016, 21, 1576.

24. Verardo, V.; Riciputi, Y.; Sorrenti, G.; Ornaghi, P.; LWT--Food Sci. Technol. 2013, 50, 732.

25. Wang, L.; Gan, C.; Wang, Z.; Liu, L.; Gao, M.; Li, Q.; Yang, C.; Molecules 2017, 22, 934.

Submitted: March 12, 2020

Published online: July 9, 2020 